\title{
Alterações nas dunas da Praia de Boa Viagem - Recife (PE) originadas por Ação Antrópica
}

\section{Sand dunes Changes in Boa Viagem Beach - Recife (PE) originated by Anthropogenic Action}

\author{
João Vitaliano de Carvalho Rocha ${ }^{1}$
}

\begin{abstract}
Resumo
O ambiente de dunas com a vegetação na região costeira tem se tornado uma das áreas do espaço geográfico que mais sofre com a ação antrópica mal planejada, ficando exposto à degradação dos seus componentes naturais. A preservação dos cordões de dunas frontais ainda é apontada como a melhor solução para prevenir uma região da erosão costeira. Para obtenção dos dados teóricos da pesquisa foi utilizado como motor de busca o site Google e as imagens de campo foram obtidas por sensoriamento remoto. O arco praial da Praia de Boa Viagem pode ser descrito como um sistema dominado por ondas e ventos, agentes responsáveis pela dinâmica sedimentar e modeladores da linha da costa. Observou-se uma perda significativa de dunas com a cobertura vegetal aceleradas por ação antrópica. Conclui-se que há uma necessidade de implantação de um manejo adequado de recuperação da área degradada que aumenta sua extensão há cada ano. Buscou-se no presente estudo entender as consequências da ação antrópica no ambiente natural da praia de Boa Viagem, Recife-PE.
\end{abstract}

Palavras-Chave: Ambiente Praial, cobertura vegetal, dunas frontais.

\begin{abstract}
The dune environment with vegetation in the coastal region has become one of the areas of the geographic space that suffers most with poorly planned anthropogenic action, being exposed to the degradation of its natural components. The preservation of the frontal dune strands is still considered the best solution to prevent a region of coastal erosion. To obtain the theoretical data of the research was used as a search engine the Google site and the field images were obtained by remote sensing. The beach arch of Praia de Boa Viagem can be described as a system dominated by waves and winds, agents responsible for the sedimentary dynamics and modelers of the coastline. There was a significant loss of dunes with vegetation cover accelerated by anthropic action. It is concluded that there is a need to implement an adequate recovery management of the degraded area that increases its extension there each year. The aim of this study was to understand the consequences of anthropic action in the natural environment of Boa Viagem beach, Recife-PE.
\end{abstract}

Keywords: Environment beach, Foredunes, Vegetation Cover.

Cómo citar: Vitaliano de Carvalho Rocha, J. (2018). Alterações nas dunas da Praia de Boa Viagem, Recife (PE) originadas por Ação Antrópica. Investigaciones Geográficas, 56, 138-152. https://doi. org/10.5354/0719-5370.2018.48066

1 Faculdade Integrada de Pernambuco. Rua dos Navegantes, 1907/402, Boa Viagem, Recife-PE. E-mail: vitalino2012@gmail.com. 


\section{Introdução}

A linha de costa é considerada uma das feições mais dinâmicas do planeta e sua posição pode ser afetada por fatores de origem natural e intrinsecamente relacionados à dinâmica costeira, tais como: balanço de sedimentos, variações do nível relativo do mar, dispersão de sedimentos e, outros de origem antrópica, como obras de engenharia, represamento de rios, destruição da vegetação de restinga, dragagens etc. As dunas costeiras são formas de relevo eólicas que se desenvolvem em situações nas quais, uma ampla oferta de sedimentos soltos, do tamanho de areia está disponível para ser transportada no interior pelos ventos do ambiente (Martinez et al., 2004). As dunas servem como proteção para impedir a progressão das ondas e a vegetação é um importante suporte para sua existência (Hesp \& Walker, 2012).

$\mathrm{O}$ ambiente de dunas na linha costeira tem se tornado um dos recortes do espaço geográfico que mais sofre com a ação antrópica mal planejada, ficando exposto à degradação dos seus componentes naturais (Sousa et al. 2012). As praias formam um ambiente dinâmico e as previsões disponíveis sugerem uma ampla gama de impactos, desde alterações na morfodinâmica por ação antrópica, energia incidente, modificações na composição do sedimento, inclinação e área disponível para ocupação pelos organismos, em condições mais amenas e/ou iniciais, até a perda da região entre marés e do pós-praia e, consequentemente, da sua biota associada a eventos extremos e recorrentes (Rosa Filho et al., 2015).

As dunas frontais são formadas por deposição de sedimentos carreados por ação eólica na área de vegetação na póspraia (Hesp, 1989; Hesp et al., 2005). As dunas são muito sensíveis no ambiente onde são formadas por serem compostas de sedimentos leves facilmente levados pela ação dos ventos (Lourenço, 2012).
As dunas, cobertas ou não por vegetação impedem a ação e a progressão do mar fixando os sedimentos trazidos por ação eólica (Ubeid \& Albatta, 2015).

O presente trabalho faz referência à praia de Boa Viagem que está localizada na zona sul do bairro de Boa Viagem, sendo considerada a praia urbana mais frequentada da Cidade do Recife. Sua densidade geográfica segundo dados do IBGE (2000) é de 136,0 hab/ha e o aumento de sua população se deveu à substituição das casas por edificações com mais de 20 pavimentos a partir da década de 1970 (Araújo, 2008, p.53).

Em todo ambiente litorâneo, o alto número destas edificações preencheu os espaços que seriam destinados às áreas verdes públicas, além de permitirem a ocorrência de forma ininterrupta dos processos naturais costeiros como os fortes ventos e o alcance das ondas nas marés de sizígia (Araújo, 2008). O autor describe que norte da praia de Boa Viagem apresenta cobertura herbácea formando um ambiente susceptível a impactos antrópicos, principalmente, pelo pisoteio constante provocado por usuários da praia que atravessam a vegetação formando caminhos que dão início ao desgaste.

As técnicas de interpretação visual de imagens são amplamente utilizadas para registrar as paisagens e as modificações observadas no ambiente ao longo dos anos são regiões homogêneas delimitadas que formarão a base do trabalho da interpretação visual de fotos aéreas, antigas e atuais, fotos locais e imagens de satélite (Panizza \& Fonseca, 2011). Coelho, Valcarcel, Neves, \& Pin (2000), Rocha, Bergallo, Van Stys, Alves, Jamel (2007) e Sá (2002) asseveram que a vegetação de restinga e manguezais compunham a vegetação nativa das praias cuja ação antrópica alterou, dando lugar a uma fazenda de cocos, tipo de cultura adaptável à região em virtude do solo arenoso encontrado nas áreas emersas e as grandes extensões de baixios sob a influência das marés. 
Costa, Araújo, Silva-Cavalcanti, \& de Souza (2008) definem praia urbana como um conjunto de estruturas formadas por calçadões, áreas de lazer para crianças, quadras, campos de futebol, jardins e prédios que passam a compor a paisagem fazendo parte da natureza social que atinge direta ou indiretamente ecossistemas naturais. A verticalização intensa no bairro de Boa Viagem trouxe consequências ambientais irreversíveis, tais como: construção de prédios, formação de ilhas de calor, aumento da vazão de esgoto, impermeabilização do bairro, desfiguração da paisagem, descontrole do tráfego de veículos, poluição atmosférica urbana por materiais particulados, aumento da demanda por recursos hídricos, impedimento da circulação do vento e sombra na praia, durante o período da tarde. Ainda, segundo o mesmo autor, o primeiro prédio construído na praia foi em 1958, porém, em 2007, já eram registrados 201 , sendo $85 \%$ destes prédios com altura acima de 10 pavimentos. A vegetação litorânea da praia de Boa Viagem, cuja extensão vai até a praia do Pina, foi considerada pela Prefeitura Municipal do Recife como Zona Especial de Proteção Ambiental, porém a construção da avenida, do calçadão, quadras, áreas de lazer influenciaram na impermeabilização do terreno e, consequentemente, na mobilização das dunas influenciando no deslocamento do balanço sedimentar (Costa et al., 2008). A figura 1 representa o modelo de formação e remodelação das dunas frontais descrito por Hesp (2002), no qual está inserido o processo de degradação e recomposição do cordão de dunas frontais que tenham sofrido alterações por causa antrópica ou fenômenos naturais.

A zona costeira da praia de Boa Viagem formada por terraço marinho holocênco foi alterado, em parte por ação antrópica, a partir da década de 1980 pelo projeto de nome Cura BeiraMar sob a responsabilidade da Empresa de Urbanização do Recife (URB), cujo objetivo era reestruturar a orla, na tentativa de oferecer uma melhor acomodação para os turistas e para a população. Porém, as intervenções provocaram desgaste no ambiente praial a partir da devastação de dunas frontais com a cobertura vegetal promovendo o rebaixamento da topografia da faixa de praia potencializando o processo erosivo natural (Silva, 2016).

Hesp (1988) cita que as dunas seguem um modelo evolutivo de médio a longo termo dividido em cinco estágios, que pode ser aplicado a costas progradantes, estáveis ou em erosão.

\section{Cobertura vegetal litorânea - Área de Preservação Permanente}

A Lei $\mathrm{N}^{\circ} 7.803$ de 18 de julho de 1989 versa no seu Artigo $3^{\circ}$ sobre as Áreas de Proteção Permanente na qual estão inclusas e declaradas pelo Poder Público, as florestas e demais formas de vegetação natural destinadas a atenuar a erosão das terras e fixar as dunas (Machado, 1991). O impacto antrópico causado por mau uso das áreas vegetadas pode promover modificações ou levar à destruição do ecossistema. Altos níveis de perturbações resultam em um decréscimo na altura e cobertura da vegetação deixando o terreno exposto e vulnerável às ações erosivas (Hesp, 2002). Apesar dos impactos que vêm ocorrendo neste ecossistema poucos estudos têm sido realizados em relação à destruição das dunas com cobertura vegetal e, principalmente, na recomposição das áreas destruídas (Rosa \& Cordazzo, 2007). O objetivo deste estudo é realizar um levantamento da ação antrópica sobre as dunas e cobertura vegetal da praia de Boa Viagem (PE) das três últimas décadas.

A cobertura vegetal das dunas constitui o principal elemento natural capaz de proteger eficientemente o solo e o relevo exercendo um importante papel na formação e fixação das dunas, e a sua variação depende do grau de tolerância das espécies vegetais em relação à deposição de areia sobre elas. Leite 


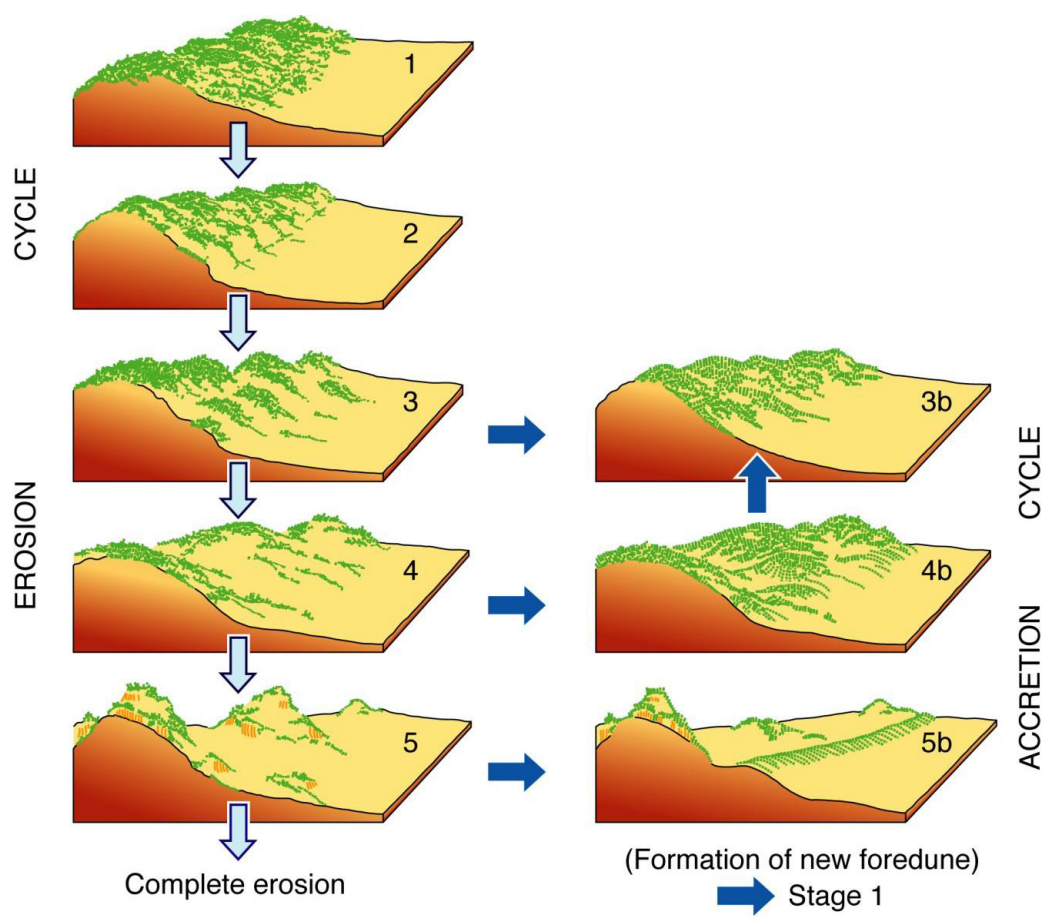

Figura 1. Sequencias do processo de erosão e recomposição do sistema de dunas. Fonte: Hesp

(2002).

Figure 1. Observed sequences in the erosion and restoration of the dune system. Source: Hesp (2002)

\& Andrade (2004) encontraram 47 espécies de plantas recobrindo as dunas distribuídas em 20 famílias e 43 gêneros, na grande maioria, herbáceas, entre elas, as espécies Crotalaria retusa (mato-pasto-roxa), Ipomoea littoralis (salsa-de-praia-branca), Ipomoea pes-caprae (salsa-da-praia-roxa), Turnera ulmifolia (chanana), Sporobulus virginicus e Paspalum maritimum são consideradas como fixadora de dunas. Nas análises realizadas em coleções de herbáreos.

Leite \& Andrade (2004) verificaram que a espécie R. marítima esteve presente na praia de Boa Viagem até o ano de 1987. A cobertura vegetal que compõe a estrutura de dunas ao longo da praia de Boa Viagem é considerada, segundo o atual Código Florestal, Lei n.12.651/12, como Área de Preservação Permanente (APP), por fixarem as dunas e atenuarem a erosão do solo (Lourenço, 2012). A área de preservação permanente pode ser definida como uma área protegida, coberta ou não por vegetação nativa, com função ambiental de preservar recursos hídricos, a paisagem a estabilidade geológica e a biodiversidade, facilitar o fluxo gênico de fauna e flora, proteger o solo e assegurar o bem-estar das populações humanas (Ministério do Meio Ambiente, 2013).

\section{Metodologia}

A proposta deste estudo é apresentar o quadro de degradação das dunas frontais que ocorreu a partir do ano 1989 na praia de Boa Viagem, com o conhecimento e aprovação da administração pública do município. Para realização deste estudo foi utilizado como motor de busca o site Google, do qual foram extraídos artigos de importantes aportes teóricos, tais como: Hesp (1981), 
Rosa \& Cordazzo (2007), Araújo (2008) entre outros citados nas referências. As saídas de campo para obtenção das imagens ocorreram no ano de 2011 entre os meses de julho a setembro.

\section{Caracterização da área de estudo}

A praia de Boa Viagem está localizada no bairro de Boa Viagem, sempre serviu de veraneio albergando poucas casas secundárias. Limita-se ao norte com o Bairro de Brasília Teimosa e o Porto do Recife, ao sul, a Praia de Piedade que pertence ao município de Jaboatão dos Guararapes, a oeste, com os manguezais e a leste com o Oceano Atlântico (Silva, 2000). A figura 2 apresenta a área do município de Recife na qual aparece em vermelho no quadro menor à direita, a área do bairro de Boa Viagem, na qual, se encontra delimitada, a praia objeto deste estudo.

O crescimento de vegetação, associado ao transporte eólico promove o crescimento de dunas paralelas à praia, com um elevado grau de continuidade, principalmente, quando não há uma influência externa capaz de promover alteração nesse equilíbrio dinâmico das forças naturais do ambiente costeiro.

A avaliação da vulnerabilidade da área em estudo, cuja resiliência vem sendo ameaçada nas últimas décadas baseou-se nos conceitos propostos por Tabajara, Gruber, \& Portz (2012) através de parâmetros que resumem a condição sistemática das dunas entre eles: área superficial, processo de escarpamento, estágios evolutivos e declividade na face frontal marinha. Os principais parâmetros que resumem a condição sistemática das dunas foram taxados com notas de 0 a 4 sendo que, a primeira representa uma condição de equilíbrio e a última, um estágio avançado de degradação. Os parâmetros foram agrupados em quatro seções:

Seção A (morfologia da duna) referese à possibilidade de regeneração das dunas após eventos de estresse ambiental e está relacionada à própria extensão e volume, portanto, quanto maior o sistema e maior a disponibilidade de sedimentos, melhores serão as relações ecológicas e geomorfológicas juntamente com a proteção contra a ação erosiva eólica e marinha.

Seção B (condição de praia) refere-se ao pós-praia e está relacionada ao suprimento de sedimentos para as dunas frontais. A largura da praia é diretamente proporcional à disponibilidade de sedimentos.

Seção C (característica dos 200 m adjacentes ao mar) contém parâmetros mais abrangentes que sintetizam o âmbito biofísico. Áreas de blowout dentro do sistema, brechas no sistema de dunas;

Seção D (pressão de uso) corresponde a elementos de natureza antrópica que afetam diretamente o equilíbrio das dunas frontais. Presença de quiosque na praia, nível de urbanização, acessos de veículos, caminhos de pedestres.

As imagens de campo foram obtidas, através de uma máquina fotográfica modelo Sansung Lens ES95 e imagem do Google Earth para demonstrar a extensão da destruição das dunas com a cobertura vegetal. Para obtenção dos dados utilizouse como motor de busca o site do Google. Por falta de informações adequadas para caracterizar as observações apresentadas nesta pesquisa é que lançamos mão de imagem a partir do Google Earth na qual utilizamos a régua disponível no quadro apresentado na figura 3 para estabelecermos a medida referente à destruição completa das dunas com cobertura vegetal, na área central da praia de Boa Viagem, na década de 1980 e que permanece até os dias atuais. O comprimento total da linha atinge 1.850,33 metros, área de dunas com cobertura vegetal devastada sem a possibilidade de recuperação natural em curto prazo. 


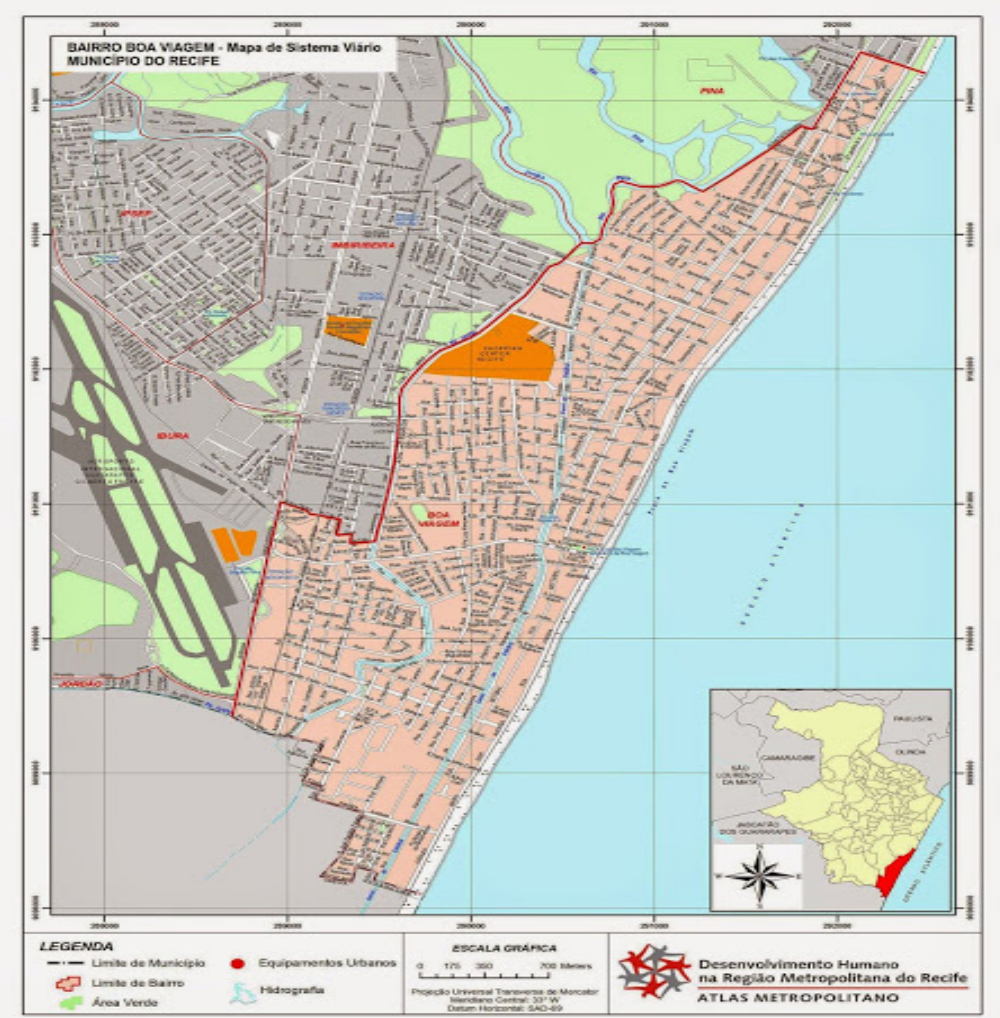

Figura 2. Bairro e Praia de Boa Viagem, Zona sul da Cidade do Recife/Pernambuco, Brasil. Fonte: https://mapasblog.blogspot.com/2012/03/mapas-de-recife-pe.html

Figure 2. Boa Viagem neighborhood and beach, south zone of the city of Recife / Pernambuco, Brazil. Source: https://mapasblog.blogspot.com/2012/03/mapas-de-recife-pe.html.

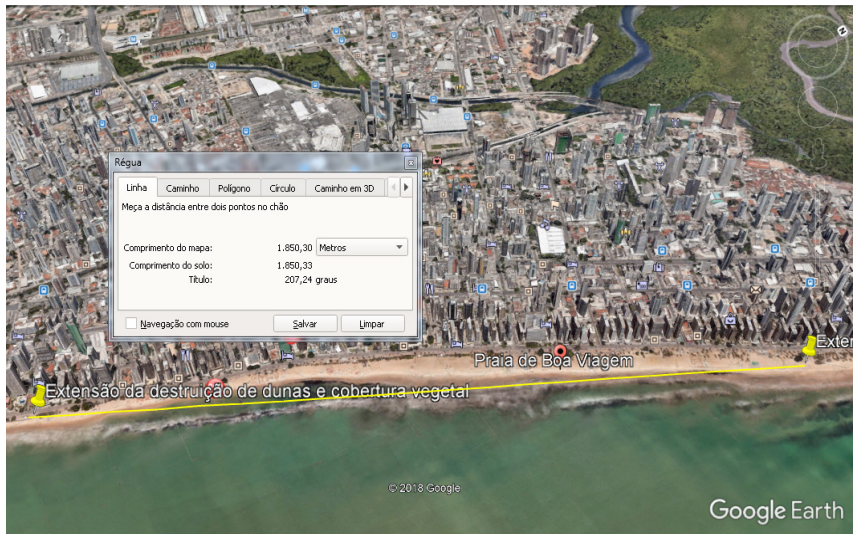

Figura 3. Extensão da Destruição de 1.850, 33m das Dunas com Cobertura Vegetal em Boa Viagem. Fonte: Google Earth/2018

Figure 3. Extension of the Destruction of 1,850, 33m of the Dunes with Plant Cover in Boa Viagem. Source: Google Earth/2018 


\section{Resultados}

Observam-se na figura 4 as feições da praia de Boa Viagem em três décadas distintas. A década de 1970 na primeira foto é possível visualizar a integridade das dunas com cobertura vegetal. Nas imagens das décadas de 1990 e 2000 vê-se claramente a raspagem da vegetação e das dunas registrando a degradação ambiental. Até o presente momento, ninguém assumiu a responsabilidade por este desastre ecológico. É possível observar a veloz verticalização deste bairro em 40 anos, com os prédios substituindo as casas.

As dunas, com altura variando de $80 \mathrm{~cm}$ a 1,20 m eram cobertas por vegetação, formada na maior parte, por capim de praia e a salsa. A retirada desse componente importante da paisagem favoreceu o deslocamento dos sedimentos da região sul para a região norte, além de sua projeção para a calçada e avenida, principalmente, no mês de agosto quando os ventos são considerados mais fortes. Observa-se na figura 4 que a faixa de terra na primeira imagem está coberta por vegetação até o ano 1989 quando foi encerrado o projeto que culminou com a destruição completa. A segunda e terceira imagens tomadas a partir de 1990 e 2000 respectivamente, não apresenta recuperação da vegetação nem recomposição das dunas frontais. Em agosto de 1994 iniciou-se o processo de erosão costeira da zona sul da praia de Boa Viagem.
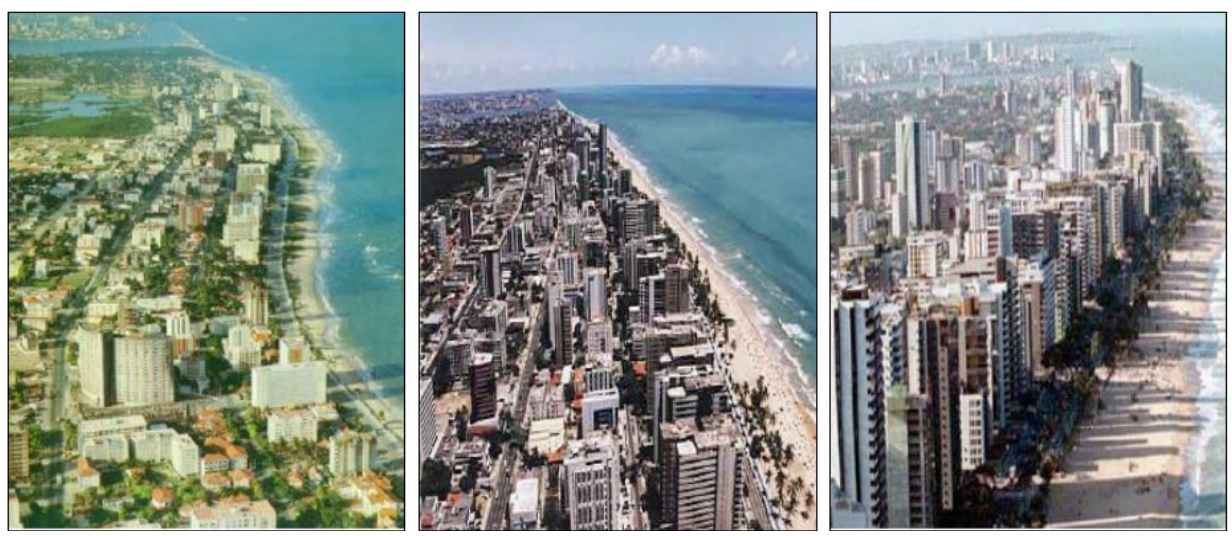

Figura 4. Degradação Ambiental da Beira da Praia de Boa Viagem nas décadas de 1970, 1990 e 2000. Fonte: Adaptada de Silva (2016)

Figure 4. Environmental degradation of Boa Viagem beachfront in the 1970s, 1990s and 2000s.

Source: Adapted from Silva (2016)

A área de mangue, antes rica de peixes e crustáceos, no alto da foto da figura 5 recebe na atualidade boa parte dos resíduos contaminados destas habitações proporcionando ao ambiente, um odor nauseabundo. As formas de vida encontradas antes, neste ecossistema tão importante, já não existem mais.

As imagens das figuras 6 e 7 encontramse inseridas no trecho cujo registro está exposto nas três imagens da figura 4. Toda a vegetação foi decomposta para dar lugar às quadras de vôlei e espaço para os banhistas.

A figura 8 situadas no norte da praia de Boa Viagem mostram três zonas diferentes, nas quais o trânsito de pessoas é sempre intenso durante todos os dias da semana, impedindo que a vegetação possa crescer.

A figura 10 mostra a destruição parcial da duna frontal. 


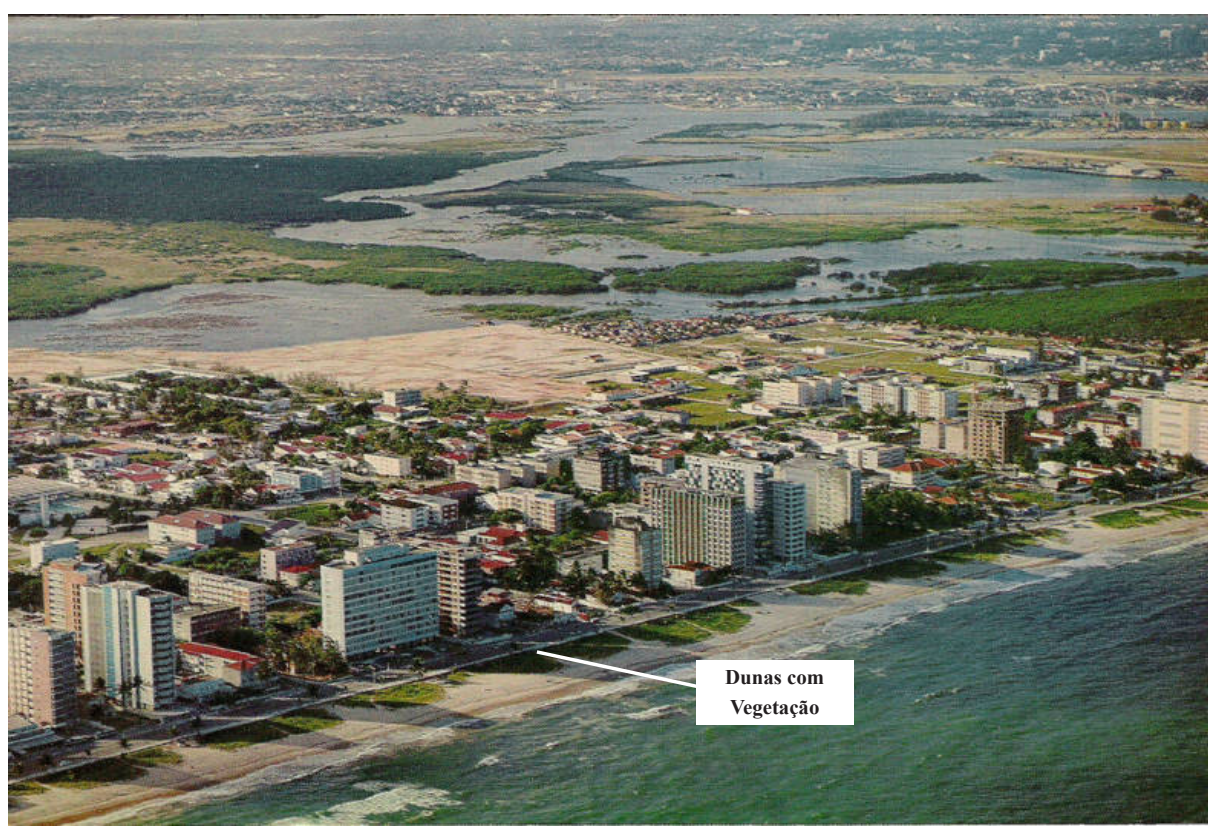

Figura 5. Vista panorâmica das dunas com cobertura vegetal praia de Boa Viagem na década de 1970. Fonte: https://divulgapernambuco.webnode.com.br/galeria-de-fotos/imagens-antigas/

Figure 5. Panoramic view of the dunes with vegetation cover beach Boa Viagem in the 1970. Source: https://ivulgapernambuco.webnode.com.br/galeria-de-fotos/imagens-antigas/

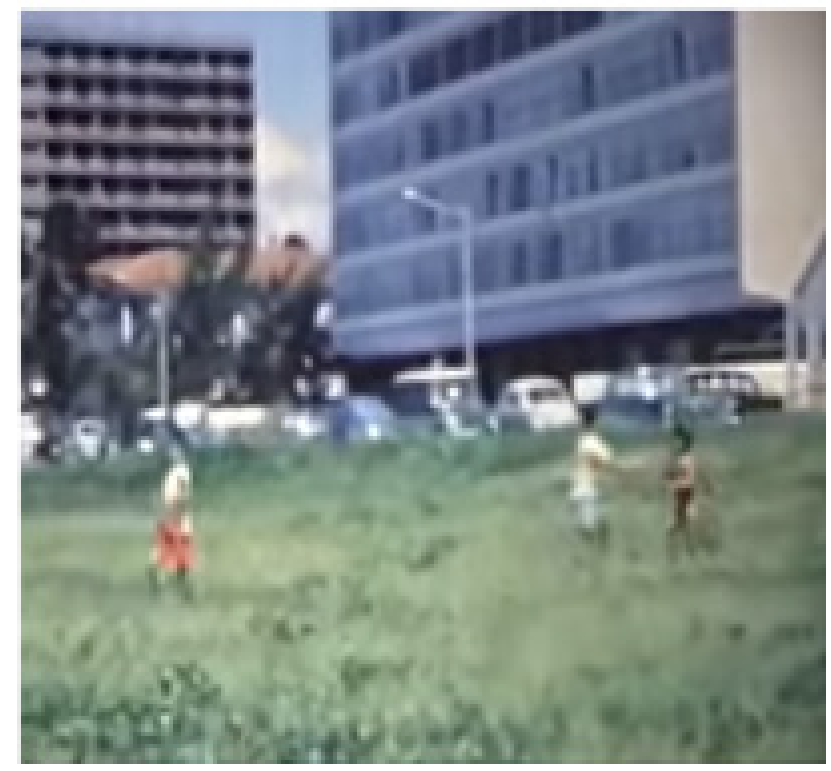

Figura 6. Cobertura vegetal e dunas em frente ao Edf. Acaiaca. Fonte: https://www.youtube.com/ watch?v=pTqcLL-GW8A

Figure 6. Vegetation cover and dunes in front of Edf. Acaiaca. Source: https://www.youtube.com/ watch?v=pTqcLL-GW8A 


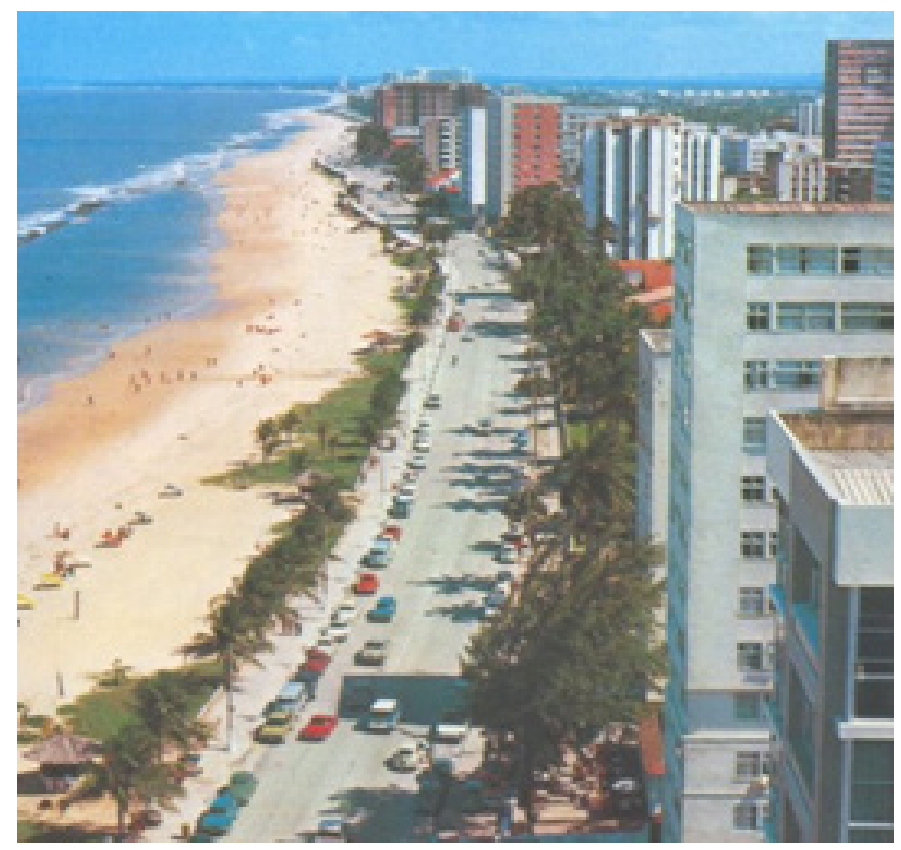

Figura 7. Destruição das dunas frontais. Fonte:https://divulgapernambuco.webnode.com.br/galeriade-fotos/imagens-antigas/

Figure 7. Destruction of the frontal dunes. Source:https://divulgapernambuco.webnode.com.br/ galeria-de-fotos/imagens-antigas/

A figura $8 \mathrm{~A}$ mostra na zona norte da praia as dunas frontais com vegetação que foram preservadas e que, nunca foram atingidas pelas marés de sizígia, mesmo nas marés de 2011 que atingiram a altura de 2.6 e 2.7 consideradas anormais para esta região, em vários meses. A figura $8 \mathrm{~B}$ apresenta área de pisoteio por banhistas, na qual existiam as dunas frontais mostradas na figura $8 \mathrm{~A}$. A figura $8 \mathrm{C}$ corresponde à destruição das dunas frontais que gradativamente vão sendo abertas pelas carroças que são levadas à área da póspraia. Observa-se nas mesmas que a areia nua facilmente será arrastada por não ter as dunas com a vegetação para impactá-las sendo empurradas na direção do calçadão, essencialmente pela ação eólica, podendo projetar areia nas calçadas e avenidas, habitações e caminhos (Portz, Manzolli, Gruber, \& Correa, 2010; Portz, Jardim, Manzolli, \& Gruber, 2016).
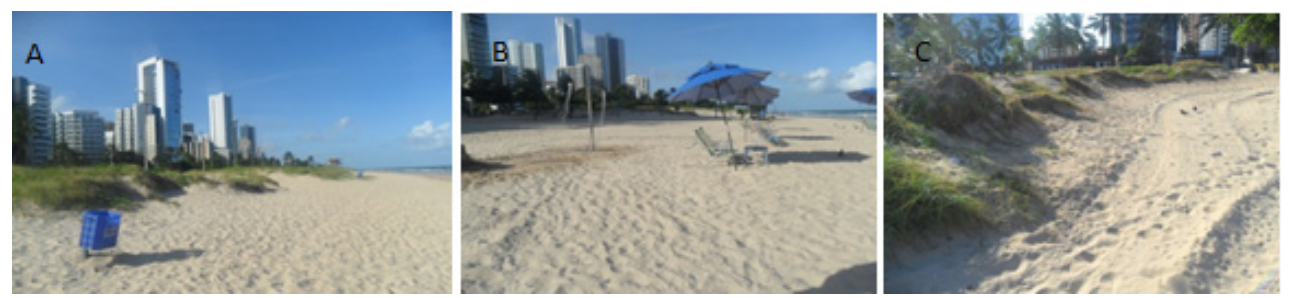

Figura 8. A: Dunas Frontais; B: Pisoteio de dunas; C: Destruição de dunas. Fuente: Elaboração própria, novembro, 2013.

Figure 8. A: Frontal dunes; B: Stepping; C: Destuction of dunes. Source: Own elaboration, November, 2013. 
Entre os meses de agosto e setembro os ventos sopram com maior intensidade projetando os sedimentos na calçada e avenida, como mostram a figura 9A. O sulco formado junto ao muro de proteção é feito pela prefeitura na tentativa de deter os sedimentos que se deslocam da pós-praia com facilidade na ausência de dunas e vegetação. A Prefeitura do Recife todos os anos a partir de julho, quando começam os ventos mais fortes cujo pico é em agosto, diminuindo gradativamente

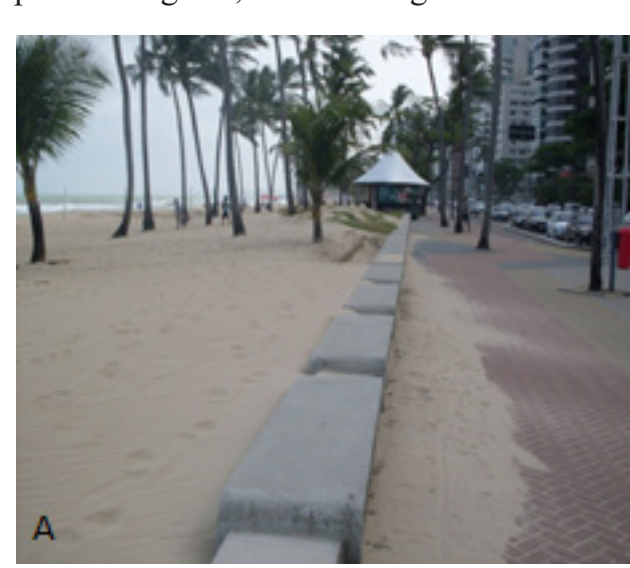

em setembro, cavam uma espécie de trincheira para receber os sedimentos trazidos pelos ventos. $\mathrm{O}$ observado na figura $9 \mathrm{~A}$ y $9 \mathrm{~B}$ correspondem à ação dos ventos no mês de julho e é possível observar o depósito de sedimentos na calçada que se estende para a avenida. Acionada a partir do incômodo à população, a Prefeitura do Recife procede desta forma para minimizar os impactos. Esse fenômeno só começou a ocorrer após a retirada das dunas.

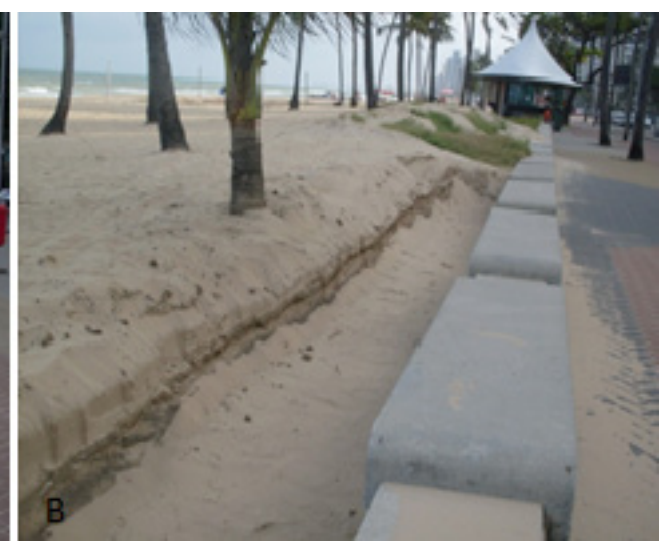

Figura 9. A: Área sem Dunas; B: Impedimento de Sedimentos. Fonte: Elaboração própria, agosto 2011.

Figure 9. A: Area without Dunes; B: Sediment impedance. Source: Own elaboration, August 2011.

\section{Consequências das Atividades Recreativas e do Pisoteamento}

As atividades recreativas podem provocar uma erosão acumulativa, que avança sobre a vegetação adjacente, reduzindo sua densidade, bem como afetar sua capacidade de acumulação de areia sobre a vegetação, ocorrendo a partir daí, uma descaracterização de todo o ambiente, o que acaba aumentando ainda mais o potencial erosivo, levando a uma grande área com perda da cobertura vegetal (Rosa \& Cordazzo, 2007). Quase sempre a ocupação ocorre em áreas de vegetação litorânea e de restinga, características de vegetação da mata atlântica, além dos bancos de areia (Mendes \& Barcellos, 2018).

A ação antrópica na área de dunas também é percebida através das trilhas formadas por pisoteamento pelos banhistas fazendo parte de uma série de processos evolutivos geológicos que refletem na morfologia costeira. O pisoteio constante leva à compactação do terreno aumentando a sua resistência à penetração, de acordo com o trabalho de Rosa \& Cordazzo (2007). Segundo Talora (2007) o impacto do pisoteio pode causar a exclusão de espécies nativas e a possibilidade do surgimento de espécies invasoras que poderiam alterar a dinâmica populacional da vegetação em grandes áreas.

As figuras 10 e 11 representam a sequência da formação de aberturas mais extensas entre as dunas e cobertura vegetal que terminam em áreas de grande destruição pelo pisoteamento constante. A figura 10A representa o início da destruição em uma área com cobertura vegetal nativa, na qual, 
pessoas caminham livremente buscando outros acessos à beira da praia. Observase na figura $10 \mathrm{~B}$ um maior desgaste na vegetação que ocorre quando milhares de pessoas durante meses ou anos usam este caminho sem se preocuparem com o desgaste. A figura $10 \mathrm{C}$ apresenta a falta de consciência ambiental quando vendedores de refrigerantes abrem sem permissão uma duna e põem, muitas vezes, fogo na vegetação rasteira. Observam-se na figura
11 A áreas de desgaste da vegetação e um novo caminho aberto nas dunas frontais. A imagem da figura $11 \mathrm{~B}$ apresenta outra abertura nas dunas bastante utilizada pelas carroças e pelas pessoas para o acesso à beira da praia. A figura $11 \mathrm{C}$ exibe a dura realidade do constante pisoteamento que conduz à formação do Blowout, área, totalmente destruída apesar de ser considerada, como Área de Preservação Permanente.
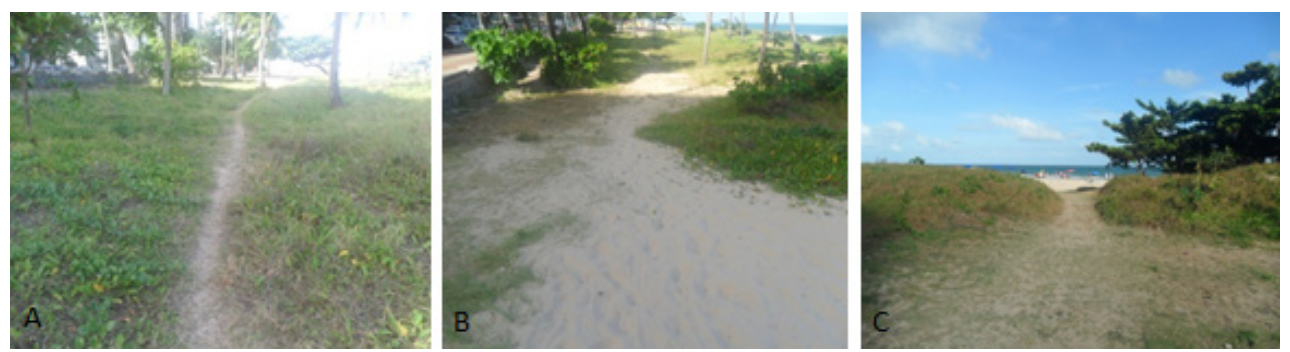

Figura 10. A: Caminho na Vegetação; B: Expansão do Caminho; C: Abertura nas Dunas. Fonte: Elaboração própria, novembro 2013.

Figure 10. A: Path in the Vegetation; B: Path Expansion; Corridor in the dunes. Source: Own elaboration, November 2013..
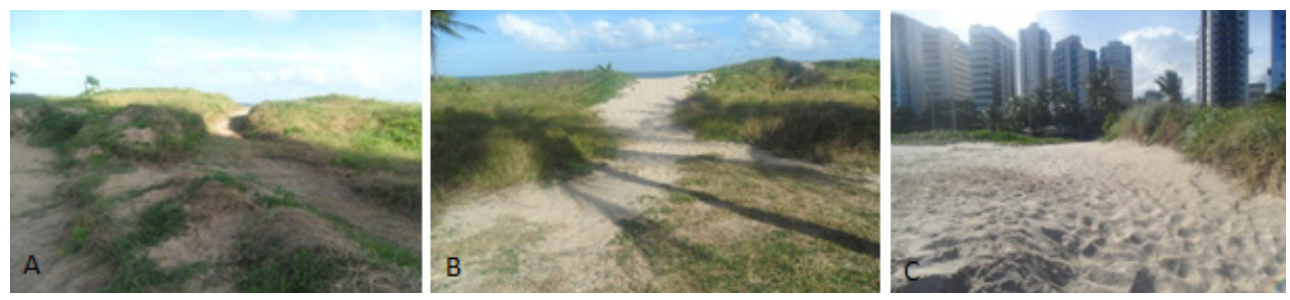

Figura 11. A: Início da Destruição de dunas; B: Caminho de carroças; C: Blowout. Fonte:

Elaboração própria, novembro 2013.

Figure 11. A: Beginning of Destruction; B: Wagon Path; C: Blowout. Source: Own elaboration, november 2013.

\section{Discussão}

Os ambientes costeiros apesar de dinâmicos são extremamente frágeis sendo utilizados nas últimas décadas, para recreação, lazer e turismo, atividades que aceleram a deformação da paisagem, principalmente por causa do pisoteio a recuperação das dunas frontais (Macedo, 2001).
A valorização cultural desses espaços pelo mercado imobiliário por causa de suas paisagens favoreceu a proliferação do desenvolvimento vertical, condomínio, estrutura hoteleira urbanizando desenfreadamente os setores mais vulneráveis do ambiente costeiro (Strohaecker, 2007). Portz (2010) assevera que com a retirada da vegetação das dunas ocorre a perda de areia 
por ação eólica e marítima promovendo a vulnerabilidade da região, que ficará exposta ao estresse causando dificuldade na recomposição (Adger, 2006).

A posição de urbanização, que ocupa a área pós-duna, está associada a uma alta densidade de vias de pedestres, que degrada a vegetação, e libera areia para o transporte eólico para as calçadas, avenidas, ruas por falta da vegetação pioneira (Hesp, 2000). As ondas, também têm grande impacto na erosão das dunas (Larson, Erikson \& Hanson, 2004); (Overton, Fisher \& Young, 1988); (Palmsten \& Holman, 2012).

As oscilações no nível dos sedimentos são progressivas na direção da terra (Sallenger \& Richmond, 1984), e com a retirada da vegetação litorânea os ventos vão delineando a linha da costa como descrevem Mahiques et al. (2010), Campos \& Dominguez (2010), Luz, Barth \& Silva (2005), principalmente por não encontrarem obstáculos naturais (Antony, Vanhee \& Ruz, 2007).

O ano de 1989 foi marcante para a praia de Boa viagem, a qual sofreu ação destrutiva de alguns barraqueiros que solicitaram ao operador do trator responsável pela limpeza da área para remover uma vasta área do Capim de Praia, vegetação nativa que é responsável pela impactação do sedimento projetado pelo vento a partir da pós-praia. $\mathrm{Na}$ ausência de vegetação, um fenômeno se observa como descreve Portz et al., 2010, 2016 sobre a areia nua que é facilmente arrastada para o interior do território, quer pela ação do mar quer, essencialmente, pela ação eólica, podendo invadir e mesmo cobrir terrenos agrícolas, projetar areia nas calçadas e avenidas, habitações e caminhos. O início da destruição ocorre, muitas vezes com a formação de um simples caminho no meio da vegetação. Em seguida, vendedores passam com suas carroças alargando a área que serve de passagem para a beira da praia. As aberturas propositais culminam com a formação dos blow-outs que caracteriza a degradação acentuada da vegetação nativa.

\section{Conclusão}

O processo de urbanização da zona litorânea nas últimas décadas tem representado grande ameaça aos ecossistemas costeiros, tanto com os ambientes de praias como, também, os manguezais. As alterações na estrutura das dunas frontais com a cobertura vegetal na praia de Boa Viagem foram propostas com o objetivo de albergar maior número de pessoas, porém, a falta de conhecimento sobre os sistemas biológicos e os processos físicos dentro do qual eles se mantêm em equilíbrio resultou na utilização inadequada com prejuízo do mesmo.

Torna-se necessário a implantação de programas de controle e monitoramento das mudanças ambientais associada a uma política urbana de proteção e reabilitação dos ambientes frágeis. Buscou-se no presente estudo entender as consequências da ação antrópica em um ambiente natural no qual foi provocada a destruição parcial das dunas com cobertura vegetal da praia de Boa Viagem, Município de Recife.

\section{Referências}

Adger, W.N. (2006) Vulnerability. Global environmental change, 16, 268-281. http://dx.doi.org/10.1016/j. gloenvcha.2006.02.006

Antony, E. J., Vanhee, S., \& Ruz, M.H. (2007). An assessment of the impact of experimental brushwood fences on foredune sand accumulation based on digital elevation models. Ecological engineering, 3(1), 41-46. https://doi.org/10.1016/j. ecoleng.2007.05.005

Araújo, M.C.B. (2008). Praia de Boa Viagem, Recife-PE: análise sócioambiental e propostas de ordenamento. (Tese doutorado,Universidade Federal de Pernambuco, Recife, Brasil. Recuperado de https://repositorio.ufpe.br/ handle/123456789/8058 
Ministério do Meio Ambiente [MMA] (2013). Código Florestal. Grupo de Trabalho Interinstitucional. Restauração e preservação de áreas de preservação permanente (APP). Recuperado dehttp:// www.mma.gov.br/port/conama/processos/ E72A2846/DispositivosLegaisAPP.pdf

Campos, R.H.S. \& Dominguez, J.M.L. (2010). Mobility of sediments due towave action on the continental shelf of the Northern coast of thestate of Bahia. Brazilian journal of oceanography, 58(spe2), 57-63. http://dx.doi.org/10.1590/ S1679-87592010000600007

Cerqueira, R. Biogeografia das Restingas. In:Esteves, F A. Lacerda, L D. (eds.) Ecologia de Restingas e Lagoas Costeiras, Rio de Janeiro: Macaé. NUPEM/URRJ, 2000.

Coelho, G. Valcarcel, R. Neves, L G. Pin, B D. ¿2000? Projeto de recuperação de áreas degradadas e plano de controle ambiental de um camping em uma APA na Ilha Grande, Angra dos Reis. In: Simp. Nacional recuperação de Áreas Degradadas, IV Resumos..., 285p. p.208209. SOBRADE. Blumenau, SC.

Costa, M. F.da, Araújo, M.C.B., SilvaCavalcanti, J.S., \& de Souza, S.T. (2008). Verticalização da Praia da Boa Viagem (Recife-Pernambuco) e suas Consequências Sócio-Ambientais. Revista da gestão costeira integrada, 8(2), 233245. https://doi.org/10.5894/rgci128

Hesp, P A. (2000). Coastal sand dunes: form and functions. CDVN Technical Bulletin. No4, Palmerston North, Nova Zelândia: Rotorua,. In: Gravel, $\mathrm{n}^{\circ} 2$. Porto Alegre, CECO/IG/UFRGS, p.104-121. 2004.

Hesp, P. (2002). Foredunes and blowouts: initiation, geomorphology and dynamics.
Geomorphology, 48(1-3), 245-268. https:// doi.org/10.1016/s0169-555x(02)00184-8

Hesp, P.A., Dillenburg, S.R., Barboza, E.G., Tomazelli, L.J., Ayup-Zouain, R.N., Esteves, L.S., ...Clerot, L.C.P. (2005). Beach ridges, foredunes or transgressive dunefields? Definitions and an examination of the Torres to Tramandaí barrier system, southern Brazil. Anais da academia brasileira de ciências, 77(3), 493-508. http://dx.doi.org/10.1590/S000137652005000300010

Hesp, P.A. \& Walker I.J. (2012). Threedimensional aeolian dynamics within a bowl blowout during offshore winds: Greenwich Dunes, Prince Edward Island, Canada. Aeolianresearch, 3(4), 389-399. https://doi.org/10.1016/j. aeolia.2011.09.002

Hesp, Patrick A. (1981). The formation of shadow dunes. Journal sedimentary research, 51(1), 101-112. https://doi. org/10.1306/212F7C1B-2B24-11D7$8648000102 \mathrm{C} 1865 \mathrm{D}$

Hesp, Patrick A. (1989). A review of biological and geomorphological processes involved in the initiation and development of incipient foredunes. Proceedings of the Royal Society of Edinburgh. Section B. Biological Sciences, 96, 181-201. https:// doi.org/10.1017/S0269727000010927

Hesp, Patrick A. (1988). Morphology, dynamics and internal stratification of some established foredunes in southest Australia. Sedimentary geology, 55(12), 17-41. https://doi.org/10.1016/00370738(88)90088-7

Larson, M., Erikson, L., \& Hanson, H. (2004). An analytical model to predict dune erosion due to wave impact. Coastal engineering, 51(8-9), 675-696. https://doi. org/10.1016/j.coastaleng.2004.07.003 
Lourenço, C.S. (2012). Dinâmica da duna frontalemfunção dasintervençõeshumanas. (Dissertação de Mestre, Universidade de Aveiro, Aveiro, Portugal) Recuperado de https://ria.ua.pt/bitstream/10773/9808/1/ disserta $\% \mathrm{C} 3 \% \mathrm{~A} 7 \% \mathrm{C} 3 \% \mathrm{~A} 30 . p d f$

Luz, C.F.P. da, Barth, O.M., \& Silva, C.G. (2005). Spatial distribution of palynomorphs in the surface sediments of the Lagoa do Campelo lake, North region of Rio de Janeiro State, Brazil. Acta botanica brasilica, 19(4), 741-752. http://dx.doi. org/10.1590/S0102-33062005000400009

Macedo, S.S. (2001). Produção da paisagem urbana contemporânea no final do século 20. Paisagem e ambiente, 14, 143-170. https://doi.org/10.11606/issn.2359-5361. v0i14p143-170

Machado, P.A.L. (1991). Direito Ambiental Brasileiro. São Paulo: Revista do Tribunais Ltda.

Mahiques, M.M. de, Sousa, S.H. de M. e, Furtado,V.V., Tessler,M.G., Toledo, F.A. de L., Burone,L., ... Alves, D.P.V. (2010). The Southern Brazilian shelf: general characteristics, quaternary evolution and sediment distribution. Brazilian journal of oceanography, 58(spe2), 2534 . http://dx.doi.org/10.1590/S167987592010000600004

Mendes, T.M. \& Barcellos, C. (2018). A dimensão territorial do esgotamento sanitário: o caso do Recreio dos Bandeirantes, Rio de Janeiro, Brasil. Ciência e saúde coletiva, 23(2), 647658.http://dx.doi.org/10.1590/141381232018232.27732015

Overton, M.F., Fisher, J.S., Young, M.A. (1988). Laboratory investigation of dune erosion. Journal of waterway, port, coastal and ocean engineering, 114(3), 367373. https://doi.org/10.1061/(asce)0733- 950x(1988)114:3(367)

Palmsten, M. L. \& Holman, R.A. (2012). Laboratory investigation of dune erosion using stereo video. Coastal engineering, 60, 123-135. https://doi.org/10.1016/j. coastaleng.2011.09.003

Panizza, A. de C. \& Fonseca, F. P. (2011). Técnicas de interpretação visual de imagens. GEOUSP. Espaço e tempo, São Paulo, 30, 30-43. https://doi.org/10.11606/issn.21790892.geousp.2011.74230

Portz, L.C., Manzolli, R.P., Gruber, N.L.S., \& Correa, I.C.S. (2010). Tourism and degradation in the coastline of Rio Grande do Sul: conflits and managment. Desenvolvimento e Meio Ambiente, 22, 153-166. http://dx.doi.org/10.5380/dma. v22i0.20351

Portz, L., Jardim, J.P.de M., Manzolli, R.P., \& Gruber, N.S. (2016). Impactos no Sistema de dunas: Dinâmica Natural versus Interferência Antrópica. Ambiente \& Sociedade, 19(3), 135-154. Recuperado de http://www.redalyc.org/articulo. oa? $\mathrm{id}=31748020008$.

Rocha, CFD., Bergallo, HG., Van Stys, M. Alves, MAS., \& Jamel, CE. (2007). Os remanescentes dos habitats de restinga na Floresta Atlântica do estado do Rio de Janeiro, Brasil: perda de habitat e risco de desaparecimento. Brazilian journal of biology, 67(2), 263-273. http://dx.doi. org/10.1590/S1519-69842007000200011

Rosa Filho, J S., Nascimento Corte, G., Fabricio Maria, T., André Colling, L., Regina Denadai, M., Cruz da Rosa, L., ... Zacagnini Amaral, A.C. (2015). Monitoramento de longo prazo da microfauna bentônica entre marés de praias arenosas. In A. Turra \& MR. Dendai (Orgs.), Protocolos para o monitoramento de habitats bentônicos costeiros. Rede de monitoramento de habitat 
Bentônicos Costeiros, ReBentos (pp.194208). São Paulo: Instituto Oceanográfico da Universidade de São Paulo. Recuperado http://books.scielo.org/id/x49kz/pdf/ turra-9788598729251-15.pdf

Rosa, L.S. \& Cordazzo, C.V. (2007). Perturbações antrópicas na vegetação das dunas da Praia do Cassino(RS). Cadernos de ecologia aquática, 2(2): 1-12. Recuperado de http://www.cadernos.ecologia.furg.br/ images/artigos/16_Rosa\&Cordazzo.pdf

Sá, C.F.C. (2002). Regeneração de um trecho de floresta de restinga na Reserva Ecológica Estadual de Jacarepiá. Saquarema, Estado do Rio de Janeiro: II - Estrato arbustivo. Rodriguesia. 53(82), 5-23. Recuperado de http://www. scielo.br/pdf/rod/v53n82/2175-7860rod-53-82-0005.pdf

Sallenger, A.H. \&Richmond, B.M. (1984). High-frequency sediment-level oscillations in the swash zone. Marine geology, 6(14), 155-164.https://doi.org/10.1016/00253227(84)90148-8

Silva, C.F. (2016). Intervenção urbana e uso do solo na zonal sul do Recife: análise sobre as transformações urbanas dos bairros do Pina e Boa Viagem. Caderno de geografia, 26(45), 55-78. https://www. redalyc.org/articulo.oa?id=333243260004

Strohaecker, TMA. (2007). A Urbanização no litoral Norte do Rio Grande do Sul: Contribuição para a Gestão Urbana Ambiental do município de Capão da Canoa. (Tese Doutorado em Ciências, Universidade federal do RIO Grande do Sul, Porto Alegre, Brasil). Recuperado de http://hdl.handle.net/10183/10086
Tabajara, L.C.A., Gruber, N.S., \& Portz, L.C. (2012). Dunas frontais de XangriLá, litoral Norte do RS: inventário, classificação e escolha de áreas prioritárias ao manejo. Pesquisas em geociências, 39(1). Recuperado de http://seer.ufrgs. br/index.php/PesquisasemGeociencias/ article/view/35812

Talora, D.C. (2007). Efeitos do pisoteio experimental sobre a vegetação de dunas do Parque Estadual da Serra do Mar,Picinguaba. Ubatuba. São Paulo. (Tese de Doutorado, Universidad de São Paulo, Sao Paulo, Brasil) Recuperada de http://www.teses.usp.br/teses/ disponiveis/11/11150/tde-18042007143653/en.php

Ubeid, K.F. \& Albatta, A.S. (2015). Sand dunes of the Gaza Strip (southwestern Palestine): morphology, textural characteristics and associated environmental impacts. Earth sciences research journal, 18(2), 131-142. http:// dx.doi.org/10.15446/esrj.v18n2.37238 